\title{
The reality of evaluating digital content based on performance standards for sciences in the middle school in Makkah
}

\author{
Dr.Haneyah Abdullah Saadawi \\ ASSOCIATE PROFESSOR - COLLEGE OF EDUCATION - UMM AL-QURA UNIVERSITY - KINGDOM OF SAUDI ARA
}

\begin{abstract}
:
The study aimed to uncover the reality of evaluating digital content based on performance standards for the science course in the intermediate stage in Makkah. The study used the descriptive approach to conduct a qualitative analysis of the phenomenon under study. The study is based on monitoring the reality of evaluating digital content, and analyzing its dimensions and interactions, by asking students while studying science content remotely in the intermediate stage. The study determined the performance standards for female students to acquire skills in digital content in the science course in the middle stage, and analyzed the reality of the phenomenon in the light of performance standards, and concluded that there are deficiencies that impede students' acquisition of skills in the digital content of the science course in the middle stage. The study found that there is a gap between the reality of evaluating the digital content for the students 'acquisition of their skills and what they should be in light of the performance standards of the students during their study of the science course in the middle stage. The study ended with determining the requirements for improving the digital content evaluation for science, which is based on the performance standards of middle school students in Makkah.
\end{abstract}

Key words: evaluation - digital content - performance standards - science

the realism and continuity of technological development, and for its success in bearing its fruits. Hence, it can be said that performance standards are a modern type of evaluation that measures students 'performance based on specific criteria instead of comparing their performance with the performance of their colleagues, and the emergence of new evaluation methods capable of Providing a comprehensive and honest picture of students' performance instead of relying on traditional evaluation methods that focus on objective tests, but rather include various types of evaluation based on performance standards that require the student to carry out tasks dealing with problem-solving, investigation, use of augmented reality, implementation of projects and keeping a file to save his work (WestEd , 2000). Therefore, the evaluation must be a mechanism of development, not separated from its activities and activities. From this standpoint, the current study comes in the context of relentless efforts being made at the level of public and private education to fulfill the quality of elearning for digital content based on the performance standards of the science course.

\section{The study Problem:}

It is determined in the following main question: 1- What are the websites for evaluating the digital content based on the performance criteria for the science course in the middle stage in Makkah? 2- What are the performance

\section{Introduction:}

The evaluation process is considered one of the basics for the success, continuity and development of any business and this includes the production of digital educational materials. In order to ensure the quality of digital materials and their ability to achieve the goals for which they were developed, there must be standards that are used to evaluate digital content and then measure performance. (Sharman, 2019)indicated that these standards define the skills and knowledge that students should acquire. It is during the performance of digital content. Often the evaluation based on standards is after developing the standards and in the light of which the performance is evaluated, as it is viewed by linking the evaluation to the curriculum, and comparing students 'performance with the standards and not with each other. Digital content is an element of the curriculum, and it can be presented in forms and means.Numerous considerations of student groups, their capabilities and circumstances. Digital content may take forms such as regular texts, interactive and non-interactive multimedia, video, audio, talking books, etc. This great potential of digital media in providing educational content for the science course makes its evaluation process more difficult due to the need for the evaluation to see the topic according to specialization. Evaluation, in its comprehensive modern sense, is the real guarantee for 
standards and performance standards. Content standards refer to what the test students are expected to know and be able to perform, such as: Conducting an experiment to determine the density of certain materials. As for the performance criteria, it refers to the level of performance that the test student is expected to show according to his classification into levels, such as: basic, proficient and advanced and its relationship to content standards.

Defining performance standards:

It is often used with two types of straightening tools, which are as follows:

1- Tasks in the performance-based assessment: it represents one of the learning outcomes based on standards, so its adoption is important for designing its tools and uses. There is no agreement on how to use performance standards and link them to evaluation tasks. One of the ways to build it is to separate the content standard so that all its components can be addressed, which are often complex and deal with more than one skill or knowledge aspect. Example: Some systems formulate more than one performance standard for each content standard, so that each represents the level of performance expected in a particular class through comparison. The content standard that states students understand that science is an ongoing and creative process and scientific knowledge is constantly changing Performance Standard: Students will be able to: Use multiple sources to answer questions related to science Acquire information about scholars Explain how the development of scientific knowledge of science has brought about changes over time. Performance tasks are evaluated on quantitative or qualitative measures and are holistic or analytical.

2- The use of performance standards in the traditional evaluation: The test questions represent the target performance standards and interpret the scores in the light of their levels. The evaluation of digital content based on performance standards in the current study is the process of collecting information and data on how to perform requests, understand them, acquire the skills of the educational material, analyze and interpret them with the aim of issuing a judgment or decision-making for the purpose of improvement and development. It helps teachers to follow the development of learning and discover problems in teaching strategies or evaluation methods. Followed with a view to developing it; It also helps the student to identify her weaknesses and to identify the knowledge and skill gaps on the subject she is learning. (Al-Sharman, 2019) indicated that there are criteria for evaluating female science students in middle school in Makkah? 3- What are the requirements for improving the evaluation of science students in middle school in Makkah in light of the performance criteria? The limits of the study: This study was limited to the strategies of evaluating female students applied in teaching science courses based on performance standards, and through practical practice for each teacher and students during the implementation of these courses. Terminology of study:

Assessment: Assessment Calendar is defined as "examining specific events and topics against specific value criteria for the purpose of making decisions" (Paulson.1970, P.1). In (Mikhail, 2016, 43)

Digital Content Calendar: It is the process of evaluating educational design and producing digital educational material according to specific standards, principles and theories of cognitive burden, graphic design and communication. Digital content is presented in many forms and mediums, such as interactive multimedia, text, video, audio, talking books, and others. (Sharman, 2019, 213) These numerous capabilities of digital media help in providing digital content and providing students with skills and knowledge. It makes the evaluation of the subject matter studied from multiple and specialized angles, as well as taking into account all groups of students, their capabilities and circumstances.

Standards-based evaluation: It refers to measuring performance based on specific content standards. These standards define the skills and knowledge that students should acquire over a specific period of time. (AlSaadawi and Al-Shamrani, 2016, 79) They also added that the standards-based evaluation is usually after developing content, performance and knowledge standards in advance and during teaching, and this is what distinguishes it from the traditional evaluation in which the performance of students is compared to standards and not to each other. The teacher can challenge how well the student is progressing toward these standards.

Performance Standards: It is defined as describing and specifying the level that the student is expected to perform and is related to one or more content standards. Performance standards are also defined as what the student must know or be able to perform in order to achieve a certain level such as passing an exam or obtaining a grade (Allen \&Leverich, 2011) Hambleton (2000) states that the evaluation literature indicates that some educators fail to distinguish between content 
that may affect the quality of digital content outputs for the science course in the middle stage.

3- Providing recommendations and proposals to improve the evaluation of the digital content of science based on the performance standards of middle school students in Makkah.

4- Alerting specialists to the integration of knowledge and skill in the field of teaching, computer and its applications.

Objectives of the study:

The current study aims to:

1- Verifying the reality of the digital content evaluation based on the performance standards for the science course in the intermediate stage in Makkah

2- Statement of performance standards for evaluating female science students in middle school in Makkah

3- Determine the requirements for improving the digital content evaluation for science based on the performance standards of middle school students in Makkah. The evaluation methods stipulated in the science textbooks scheduled for the intermediate level may be of a high degree of comprehensiveness and diversity in terms of students 'acquisition of knowledge and practical skills, but they remain so at the theoretical level and indoctrination without practical practice, then the disparity occurs in the student's failure to acquire practical skills for the theoretical part,and

Applications .The discrepancy in itself is not a defect, as the content in the textbook determines the expected outcomes and content topics, and outlines and main paths that guide the planning and implementation of the course, and this does not eliminate the teacher's role in planning teaching and learning activities and educational experiences, and designing educational situations in line with the realities of teaching.

Remotely; The real problem is when this discrepancy is unplanned, and is the result of considerations that are not related to the objectives of the course. In the following lines, a group of phenomena and problems related to the evaluation of female students are monitored, from the reality of the daily living in the Madrasati platform, discussions between students, and discussions in meetings with teachers.

First: On the basis of reviewing the content of the science course in the middle school, the evaluation strategies can be summarized in: (1) Tests: their score is usually divided into two exams, the midterm test and the final exam; It includes essay and objective tests. (2) Achievement files: It is the compilation of the work and various tools for evaluation in learning management systems to create tests or a specific product, such as a project that the student undertakes and other means of evaluating students 'performance. We also add multimedia, drawing on the board for the cell, or writing a chemical equation or drawing an electrical circuit according to the subject being studied in science, or conducting laboratory experiments through virtual laboratories and students discussing them individually or in groups, all of which are related in order to achieve the specific educational goals of the subject of the lesson. Here, the student's mastery of the skill appears through his performance. Because of the importance of evaluation in the educational process in general and in electronic educational materials in particular, the efficiency, diversity and levels of the evaluation method should be evaluated according to specific performance standards, as well as the feedback that the student gets as a result of the evaluation

Study Approach:

The current study used the descriptive approach, using the method of qualitative analysis of the phenomenon under study.

Study steps and procedures:

The first step: Monitoring and analyzing the reality of the digital content evaluation based on the performance criteria for the science course in the middle stage in Makkah through the following procedures: 1) Determining evaluation strategies while studying the science course in the middle school based on performance standards. 2) Monitoring and analyzing a sample of situations, discussions, problems and practical experiences related to evaluating female students while studying the digital content of the science course in the middle stage.

The second step: Determining performance standards, by referring to recent research and literature in the field of Evaluation strategies and tools.

The third step: Determine the requirements for improving the digital content evaluation for science based on the performance standards of middle school students in Makkah.

The importance of studying:

The importance of this study is determined as follows:

1 - It represents a kind of self-evaluation in the context of continuous development trends.

2 - It seeks to find solutions and proposals based on the results of scientific research, to overcome real problems 
the teachers responsible for teaching the course itself. The final exams for the course are uniformly timed, and the exam time is uniform, but the objectives that measure them, the type of questions, and the level of difficulty differ according to the teacher. This means that the female students graduating in one batch are not subject to unified standards in determining their level of academic achievement.

3. There is no clear distinction in practice between free school activities and free school activities

\section{Educational purposes for evaluation:}

The purposes of the evaluation relate to the teacher and the student as the two poles of the educational process learning. These objectives revolve around one main objective: to improve the teaching and learning process, and they can be summarized as follows:

1- Evaluation purposes related to the teacher: The teacher conducts this evaluation in order to obtain information that is useful in knowing the performance of his students and their progress during the course of the education process, to know their strengths and weaknesses, and to reveal their abilities, aptitudes, their preferences, aspects of their activity and the progress they have made.

2- Assessment purposes related to the student: For him, an effective calendar is a strong motivation for his activity and learning. It also directs the path of the learning process and pushes it in the appropriate direction by introducing the learner to the extent of his progress in his learning and success, as well as a feedback that provides him with information about his performance. Numerous researches have shown that the type of feedback is an important variable in the learning process and leads to acceleration and improvement of the learning process, and the retention of the learned material. Studies have shown that evaluation that focuses on complex learning outcomes, higher levels of learning, broad applications, and scientific principles that help explain various scientific phenomena increase the possibility of learning transmission. Finally, the assessment tool is a learning tool, so the test is considered exercises or standardized exercises that benefit the student directly. He uses the results to verify the correctness of the answer and prove it if it was correct and exclude it if it was wrong.

\section{Realistic or alternative evaluation:}

It is a type of multi-alternative evaluation in which students are asked to complete realistic life tasks in order assignments that the students carried out during the implementation of the course activities by drawing the student and putting the picture in the file. (3) Self and practical evaluation: It is usually referred to in the course as the title, without specifying its weight in the final evaluation of students. (4) Practical exercises: Sometimes they are mentioned as a title, without specifying their relevance to the course, especially when they are placed in predominantly theoretical courses, without paying attention to the practical part such as drawing the cell, an electrical circuit or writing a weighted equation on the interactive whiteboard on the platform, or giving a link to virtual laboratories And developing activity sheets on it or creating videos of scientific experiments according to the content of science taught in middle school (5) and direct observation. (6) Research projects with assignments using technology (7) and performance tests. (8) Assignments to individual class offers. (9) And provide an evaluation feedback, according to what is found in the textbook of science course for the intermediate stage of the first semester, 2019.

The assessment tasks and activities vary according to what is stated in the science course books, which include: writing reports on course topics or related to the course vocabulary - providing abstracts - writing an essay - midexamination - producing an educational medium practical test - final exam - student projects - discussions and group participation - Participations during the lessons - Evaluating the duties of practical training in producing the means and conducting practical experiments or drawing a cell or electrical circuit. This is about evaluating female students from the reality of science books for the intermediate level. What about the calendar from practice? A group of phenomena related to the evaluation and its results can be monitored from the reality of practice, during the implementation of the course, the most important of which are: 1 . At least $30 \%$ of the total grade that students obtain in the course is for activities that they carry out within the lessons, or even outside them, Example: 1. Preparing presentations of course topics, explaining some topics, summarizing topics, collecting scientific material from various sources of information, producing educational aids, and participating in exhibitions and activities at the school level.

2. The timing of the mid-term examination, the objectives that it measures, the type of questions, their content, and the level of difficulty vary widely between 
time in which it takes place, but rather accompanies all stages of the learning process, inseparable from it, but rather an integral part of it. Realistic evaluation methods are not structured as is the case with multiple-choice or standardized tests, but rather they contain projects that require students to use problem-solving skills, analyze information and synthesize it in a new context."(Shehata, Al-Najjar, and Ammar, 2009, 66) and requires realistic evaluation. The following conditions are met: Focus on the student's ability to use the knowledge obtained, and provide students with fully organized tasks within the framework of distinct teaching activities, including conducting research and writing reports on virtual practical experiences, for example, working papers, revising and discussing them, and providing the opportunity to participate in oral discussions and cooperation with others, and focus To the extent of the student's ability to reach answers or arrive at an elaborate, comprehensive, and adequate performance or product; to provide accurate and clear criteria for judging the product or performance; to provide tasks and problems that challenge the student and allow him to practice dealing with life situations that are characterized by a degree of ambiguity and complexity; Often the true calendar takes the form of a performance-based assessment.

\section{Performanceevaluation:}

The Bureau of Evaluation Technology in Congress in 1992 defined performance evaluation: "as experimental methods that require the student to produce an answer or create a product that demonstrates his knowledge and skill.

http://ota.fas.org/technology_assessment_and_congress/ It is characterized by three main features: (1) the answers are produced and not chosen from among alternatives, (2) the students observe while they carry out tasks closely related to what they perform in their daily lives, and (3) the students explain the thinking processes and strategies they follow throughout the task completion stages.

The performance evaluation includes two basic terms:

The first term: it is the performance, so students produce the answer that is observed directly or indirectly through a product, and the second term: it is the real or authentic, and it means that the nature of the task and the context in which the evaluation is carried out is related, for example, to real life problems. . Lam T.C.M. (1995) ERIC No. ED 391982 The realism of the performance evaluation is achieved when it takes into account both for the student to appear through his accomplishment of this task, his ability to apply the skills and employ the knowledge he acquired. In a simplified definition, it is a realistic evaluation of the student's performance, showing the true level of knowledge and skills acquired through his educational journey and real-life situations; it is sometimes called a performance-based assessment (Mikhail, 2016, 351). With the shift in the philosophy of education and linking it to students' lives, evaluation systems evolved. They are no longer limited to traditional seasonal exams, which do not faithfully reflect real learning; Whereas, basic education programs are responsible for graduating students who possess the knowledge and ability to apply them and transform them into practical life practices. Therefore, tests alone are not sufficient to verify the quality of the outputs of basic education programs. Hence, the necessity to shift to the alternative or realistic evaluation, which reflects students' performance and measures it in real situations while they engage in meaningful tasks for them through their study of digital content on the My School platform remotely; Students in realistic evaluation activities are busy completing tasks that require them to practice higher-order thinking skills and link areas of knowledge to make judgments, or to make decisions or solve problems closely related to their lives, and thus they develop the ability to think reflective that helps them to process, criticize and analyze information. Realistic evaluation strengthens the link between teaching and learning; it encourages self-evaluation and lifelong learning. The value of applying the realistic evaluation strategy does not stop in evaluating female students in the basic education program while they study the science course, but goes beyond it to being practical training and coexistence with real experiences, through which students imbibe knowledge, skill, values and trends that are an essential part of their personal formation and their competence in performing the roles that Required by realistic evaluation strategy, and in applying its methods; The adoption of realistic evaluation methods requires a change in the roles that the student has become accustomed to inside and outside the classroom. The teacher is no longer the only one concerned with the evaluation process. Rather, many parties participate in it, at the forefront of which is the student himself. Equally important - observing the student, measuring his participation in learning activities, and his attempts and procedures to accomplish the learning tasks, and the seasonal calendar is no longer governed by a specific 
From the foregoing, the components of realistic evaluation can be grouped into five main dimensions, which are:

1) The objective of the evaluation process: evaluating learning outcomes and outputs, and its procedures, and providing feedback for the purpose of improvement and development.

2) Timing of the evaluation process: Evaluation is a continuous process, part of teaching and learning activities, and takes place in the natural context of teaching and learning situations, in addition to the existence of a final evaluation.

3) Responsibility for evaluation: There are many parties involved in the evaluation process, to include the teacher and students

4) The aspects that make up the evaluation process: The aspects of the evaluation process are multiple, including determining the specifications of the final product to be completed, agreeing on evaluation criteria, determining the available time range for completion, and providing models Examples explaining to students what their product should be, assigning students to tasks and assignments that highlight the integrity of knowledge, and emphasize the link between the academic content and students' lives and the world in which they live, note the various aspects of the student's personality, interest in the product and the procedures that were followed to reach it.

5) Tools used in the evaluation: There are many methods and methods of evaluation that include tests, achievement files, projects, reports, and evaluation measures. To what extent can the realistic evaluation strategy contribute to meeting the criteria of the evaluation?

The following is an outline of the realistic evaluation guarantees:

- The realistic evaluation requires a clear understanding on the part of students of the nature of the tasks and assignments required of them, the criteria for judging the quality of their achievement, the way they are held accountable for their achievement of learning tasks, and what they must take into account before starting the implementation of the task, and this is a guarantee for the evaluation based on performance standards until It does not interfere with factors such as ambiguity of the requirement, or differences in expectations between the teacher and students; The misunderstanding and ambiguity of the task may lead students to focus on specific aspects that they expect to be held accountable the process and the product together, and this is what bridges the gap between teaching and evaluation. One of the aspects of performance evaluation is making evaluation a component of the curriculum. This method is where the evaluation is a series of interrelated learning activities, theoretically and practically, built in a way that leads to a single, predefined goal. The performance evaluation requires producing extended responses, participating in the achievement of a product, answering open questions that require analysis, synthesis, and making judgments, observing the student's behavior in realistic, purposeful activities or situations, achieving integration between various fields of knowledge and skills, and observing the procedures and strategies that students followed to reach a response or Provide solutions on complex tasks as well as evaluate the final product. 23-25 (1991, Frechtling) The realism of evaluation requires its achievement to provide opportunities for students to self-reflection on their learning, and self-evaluation of their achievement, which means that the matter does not stop at passing a judgment on students 'production, but rather providing opportunities and providing means for them to improve this production and reach the required level. Abdallah, 2003, 24) One of the requirements of realistic evaluation is also modeling, that is, presenting models from the learning tasks that specify to learners the specifications of the final product that they are required to achieve, and the standards against which their performance will be measured. English Language Arts Overview, 2001,7) "Realistic evaluation requires teaching authentically, realistic teaching is a prerequisite for the occurrence of realistic evaluation, and in order to achieve realistic teaching, it must meet three criteria: structured inquiry, integration of knowledge, and to be through tasks that prepare students for life and not just for the exam." Burke, 1999.Xvi In sum, it can be said that the realistic evaluation is not just achievement tests or standardized tests that depend on multiple-choice questions, as the student's learning is measured by specific test questions that are applied in a specific time, require specific responses, and measure limited cognitive skills, but rather expand to include written tests in addition to procedures. Others, including: performance measures, student observation, evaluation of their products, examination of student achievement files, and review of their previous performance. (Abdallah, 2003, 12) 
complexity similar to the reality of daily life activities and their problems, and this means avoiding excessive ease and superficiality in evaluation tasks and activities and choosing and designing activities that challenge students' abilities, and stimulate their motivation to exert effort to accomplish them.

- Realistic evaluation requires transforming theoretical knowledge into realistic performance, which can be observed and measured in the appropriate natural context, and this requires tools for measuring performance based on knowledge and skill, and not limited to measuring knowledge acquisition. Evaluation tools in the balance of performance standards. - With the multiplicity of realistic evaluation methods, achievement files and tests remain the most used at the practical level in the educational preparation program, so the focus of this study will be on them in terms of guarantees for evaluation based on performance standards. Calendar using portfolios achievement files: Achievement files are one of the forms of realistic evaluation, and one of its tools. Evaluation using achievement files is a purposeful and structured collection of student work within a specified period of time Evidence and evidence of this growth. There are those who know the achievement file as a personal file for each student, which includes a group of works and activities that represent the best samples of what the student has accomplished, and the contents of the file provide a realistic and complete picture of his academic performance, and reflect his personality. (Comprehensive educational evaluation system, 2007, 72), and the achievement file includes models that prepare a representative sample of the works, assignments and projects that the student participated in completing during a specific period of time, and it includes reports on projects and tasks that he has completed or participated in, as well as samples of successive evaluations for the student in Periodic examinations, oral discussions, and the student's participation in choosing examples of his work to highlight his achievement within a specific time frame is one of the most important features of evaluation using achievement files. With the great development in the field of information technology, the electronic portfolio - E has emerged. asa technological innovator in the educational process, especially with distance education now. The electronic achievement file has increased in importance as it documents educational performance, encourages reflective thinking, and provides opportunities to return to previous experiences and and evaluated on, while the teacher holds them accountable and evaluates their achievement on other aspects that were not considered by them. Realistic evaluation depends on projects and activities, and tasks closely related to students 'lives and their reality, and for students' availability of appropriate background knowledge on assessment tasks, which reduces the interference of anxiety and fear factors and their negative impact on their performance.

- The tasks of realistic evaluation, show the ability of students to link between areas of knowledge and skill, and the use of theoretical knowledge in the completion and performance of practical tasks, as well as to show the values, habits and trends that guide students' behavior during the completion of tasks, and during their interaction with information sources, with the environment, and with materials and tools And utilities. Realistic evaluation does not deny the importance of periodic tests, formal and informal, but rather guides their use, so they are not the only basis

The evaluation tasks require their completion, the integration of knowledge, and the transmission of the impact of learning in new situations, not merely recalling information and raw facts mentioned in the course, but rather reproducing them in a way that contributes to solving a problem, or completing a work, and this is a guarantee for evaluation based on performance standards because they make it more Honesty in the expression of real learning, which is reflected in the behavior of the learner: the evaluation is not limited to specific tools and tasks, but its tasks and tools are varied, which means that students have multiple opportunities to demonstrate their knowledge and skills, benefit from their mistakes, gain various experiences, and improve their results.

- Not only focusing on the final product or the correct answer, but equally important, focusing on the methods and methods that the student used to reach the final product or solution, which reduces the interference of chance and guesswork factors in the student reaching the correct answer, and ensures that he learns methods and skills Access to knowledge, not just imparting knowledge, and this is a guarantee of the continuity of learning for life. Realistic evaluation requires agreement on evaluation standards among all concerned parties, as a guarantee of evaluation based on performance standards, because it limits the interference of subjective factors and personal impressions in the evaluation, and increases confidence in its results. Realistic evaluation requires that tasks and activities be on a degree of 
of the course learning. (6) It is included in real evidence and evidence closely related to the objectives of the course, documenting the student's achievement, (7) showing the student's personality, and the extent of his ability (8)Demonstrate the student's ability to link knowledge, and link previous experiences with later benefits, by participating in projects, activities, and realistic tasks. (9) Include graphs, pictures, illustrations, and mental maps, in order to communicate information accurately, in a simple and fast way. Appreciation measures, estimation rules, or scoring rubric are useful methods for achieving the required linkage and integration between the quantitative evaluation and the qualitative evaluation of the achievement profile. There are those who define it as "a set of criteria and criteria that are usually related to learning objectives, and are used to evaluate a product, performance, or practical tasks, and it is an attempt to agree on specific expectations to judge the quality of a task or water product" (Rubrics - Definition, Examples 2013, 2013) It is a tool used to describe the gradual levels of achievement accompanied by indicators and evidences to judge at each level. To ensure fairness and quality, the performance indicators and specifications at each level must be well-defined, publicized, and agreed upon between the parties to the evaluation process. Evaluation using tests: Tests are among the most common evaluation tools, and they still have a higher level of confidence of the parties to the educational process in their results, the ease of adjusting the test position, and the possibility of applying the test to a large group of students at the same time, which reduces the effort, time and cost of the evaluation process. For decades, exams have been subject to the subjectivity of their authors and their vision of what students should experience and how they should test. This was consistent with the fact that the curriculum does not deviate from being a study book, and the teacher is nothing but a transmitter of the knowledge contained in the book and an explanation of it, and the student's academic level is measured by the amount he memorized and sponsored from the book and from the teacher's explanation. (Mikhail, 2016, 215) Achievement tests in measuring what students have obtained in the course depend on questions of producing the answer and questions of choosing the answer, as the questions play an essential and important role. "The questions must be studied and planned, and emanating from the educational objectives and proportional in their number to The time and effort expended during the obtain feedback. The two most important features of the electronic achievement file are the attributes of selectivity and reflection. The use of the electronic achievement file has become an essential element and an essential component of the evaluation based on performance standards in schools in the United States of America (Ismail, Muhammad, 2009). Among the names of the electronic achievement file, the electronic bags over the network, and the electronic document folder. The electronic achievement file is defined as the collection of samples of the teacher's or student's work over successive periods of time, to reflect the topics he studied, the activities he practiced, the sources of information he collected, the duties he accomplished, video tapes and reports on current events, projects, and their results in Tests, reports on participations and assessments, and evidence and evidence from all work that demonstrate progress in achieving learning outcomes. The electronic achievement file is characterized by a set of characteristics, the most important of which is that it is prepared, prepared and transmitted via the Internet, its contents can be browsed by scrolling through links, allowing the possibility of documenting works and achievements using audio, video or power point files, and multiple media (AlMallah, 2018). The evaluation of the achievement files, whether paper or electronic, from a performance-based evaluation perspective, shows that the biggest challenge lies in the availability of specific criteria for evaluation of the contents of the file, and the ability to translate the qualitative assessment into a quantitative value in the form of grades obtained by the student for the entirety of his work included in the file. This requires a predetermination of the intended learning outcomes in the course, the indicators for judging the achievement of these outcomes, the evidence and evidence to be included in the achievement file to verify the achievement of these outcomes and the criteria against which the achievement file can be evaluated. (1) The file content is free from linguistic and spelling errors. (2) The output of the file, the method of presenting its contents, and displaying them according to a clear methodology, (3) the ease of viewing it and moving between its contents in the paper file, and the ease of browsing its files in the electronic file. (4) Comprehensiveness and fulfillment of all tasks, duties, and activities required passing the course, (5) its diversity in a way that shows growth in various aspects of the learner's personality, and in a way that shows the achievement of various aspects 
and its observance of the knowledge and cultural background of the examinees, and its focus on learning outcomes or targeted competencies. 4) The correction key, which has many names in the different examination systems and in the literature; It is referred to as the answer form, the score chart, the test score guide, or the answer key. It must have accurate reviews in terms of its accuracy, comprehensiveness, objectivity of the score distribution and criteria for its calculation, and its consistency with the goal that the question measures and its level of knowledge. (Mikhail, 2016, 246). Requirements for improving the evaluation of intermediate school students in the light of performance standards for science: In light of what was previously discussed in this study, the gap between the realities of evaluating female students becomes clear, as is evident from practice during the implementation of the course. And what should be the evaluation of digital content based on performance standards. This gap is what determines the future actions and steps required to be taken to achieve the evaluation.

The following is a review of these requirements:

1) That the evaluation is an essential component of teaching and learning activities within the educational platform, and that it includes the different types of evaluation; the teacher's evaluation, the students 'selfevaluation, and the female students' evaluation of some peers or groups. This is in addition to being an integral part of the teaching and learning activities of the course, it is also continuous training for female students on evaluation strategies and methods.

2) The need to agree on the standards and criteria for the evaluation of male / female students among those who teach the course. Standardization is a guarantee of evaluation, and this requires a higher degree of coordination between those who study the same course, may require Determine the course coordinator for each semester.

3) Announcing the evaluation criteria and their criteria before applying them to students; This helps them selfevaluation, and make objective and real expectations about their level, and this is one of the ways to solve the problem of students' high expectations of the degree that they will obtain in the course, despite the fact that their real achievement level places them in a middle or weak position.

4) Establishing specific and clear criteria and criteria for evaluating achievement files, with the necessity that they be closely related to the intended learning outcomes in learning process .... Therefore, the test-taker must be familiar with the sources of their derivation, how to formulate them, and their specifications, in addition to the procedures for designing and managing measurement and evaluation. (Darwaza, 2000, 2). The teacher's possession of the techniques of the question opens effective channels for him. And influential for successful communication with his students, and to obtain the highest amount of information available about their achievement. To ensure the quality of the test, the test preparation process must go through a series of basic procedures Preparing an outline for the test, which includes determining the learning outcomes to be measured by the test, analyzing them to formulate them in the form of measurable and observable behavioral goals, determining their relative weights in the course, determining the purpose of the test, the target persons and students in it, the types of questions, and their number, in light of the time available for the test . Preparing the test vocabulary, and it includes developing questions that measure each learning outcome, in light of the above Determining it at the planning stage, also if the answer to the question requires the availability of certain tools or equipment, it must be mentioned in the title of the question, and the answer form and grades should be drawn up. - Review and revise the questions, and it includes reviewing the questions to ensure the accuracy of the question's phrasing, clarity, and placement Correct punctuation, the safety of the scientific content of the question, and its relevance to the goal that was set for the measurement, leading to the questions in their final form.

ETS standards for quality and fairness(2002)

Grayson H. (2003) http://ww.utc.edu.administration/

The standards used internationally to ensure the quality of tests can be classified into four main dimensions, namely: 1) The form of the examination paper as it appears to students in terms of its coordination, clarity of instructions, completeness and quality of materials Complementary to it, such as audio recordings, texts and written materials, or drawings and figures such as tables, maps, or illustrations. 2) The techniques of the questions, in terms of their quality, sound formulation, relevance to the scientific content, and their efficiency in measuring the educational objective that they were designed to measure. 3) The scientific content of the questions: in terms of its accuracy and comprehensiveness, its representation of the content of the course, its relevance 
excessive difficulty also leads to frustration and low motivation, and the control of feelings of failure and helplessness.

\section{Rresults:}

1. The study presented a qualitative analysis of a sample of practices, and experiences from reality about evaluation strategies, and methods of applying them during the implementation of the science course in the semester by both science teachers and students.

2. The study extracted the performance criteria for the evaluation by referring to the research and literature related to the research topic.

3.The study concluded that there is a gap in the guarantees of evaluation of female students between reality and what should be.

4. The study provided a list of requirements for evaluation based on performance criteria, including: The necessity of having agreed standards to judge the students 'performance in various learning tasks and practical activities, the importance of standardizing the official test specifications and controlling the test position, the necessity of training students to practice self-evaluation, separating the subject from the subject, the importance of having rules for assessing the achievement files, and paying attention to feedback, And a distinction in evaluation between free activities and course activities.

\section{Recommendations:}

The study recommends finding greater cooperation and coordination between female teachers studying the same course, to ensure uniformity of evaluation standards and test specifications among groups studying the course. It also recommends informing students of the standards and criteria in which they will be evaluated, encouraging them to self-reflection, the constant pursuit of improving their performance, avoiding mistakes, and educating the parties involved in the evaluation process, to increase awareness of the importance of distinguishing between subject and subject and that evaluation is a constant endeavor by all parties to verify the level of achievement. And to avoid and fix defects to achieve quality performance; it also recommends the availability of a mechanism for financing student projects and activities related to the decisions, and making use of their outputs. the course, and using assessment measures to link the qualitative description to a quantitative estimate. In the end, what is monitored is an arithmetic value that represents the degree of the student.

5) Agreeing on the official test specifications in the course, in light of the targeted learning outcomes, to guide the teachers who participate in teaching the same course, to reduce the variance in the quality of the tests and their levels of difficulty.

6) Reviewing test papers to ensure the quality of questions, clarity of instructions, freedom from errors, and quality of formatting and printing.

7) Giving more attention to the answer form, to ensure that the answers are accurate and comprehensive, especially in the essay questions.

8) Controlling the factors that could affect students 'performance on tests, and the suitability of electronic test rooms for the number of students.

9) That the evaluation activities contribute to confirming the integration of knowledge and skill, and help the transmission of the learning effect in new situations, not merely summoning the raw information and facts as mentioned in the book, but rather reproducing them in a way that contributes to solving a problem or accomplishing some work; Realistic evaluation requires transforming theoretical knowledge into realistic, practical performance that can be observed and measured in the appropriate natural context. This means the need for performance measurement tools based on knowledge and skill, as well as measuring knowledge acquisition.

10) Not only focusing on the final product or the correct answer, but it is equally important to focus on the methods and methods used by the student to reach the final product or solution.

11) The existence of evaluation criteria defined, clear and agreed upon by all concerned parties, to reduce the interference of subjective factors and personal impressions in the evaluation, increase confidence in its results, and encourage student self-evaluation.

12) Avoid excessive and superficiality in the evaluation tasks and activities, especially the process, so that it challenges students' abilities, and stimulates their motivation to exert effort to accomplish them. Excessive ease leads to laxity and low motivation. Likewise, 


\section{List of references:}

-Ismail, Muhammad Ismail (2009).Electronic Achievement File, E-Learning Magazine, Second Issue, (Aug. http://emag.mans.edu.eg/index.php?page-news\&task-show\&id-202\&sessionID-11

-Alington Heights, Illinios.p.xvi.- Carter V. Good; Dictionary of Education, McGraw Hill Book Company, USA, 1973.P220.

- Congress, Office of Technology Assessment. (1992Februry).

http://ota.fas.org/technology_assessment_and_congress/

- English Language Arts Overview.(2001). http://www.Sasked.gov.sk.ca/docs/ela

20/bulletin/overview - ETS standards for quality and fairness (2002), Educational testing service, ETS,

Princeton, NJ 08541

http://ww.utc.edu.administration/WalkerTeachingResource Center/Facultydvelopmeant

- Frechtling, J.A. (1991): Performance assessment: Moonstruck or the real thing? Educational Measurement: Issues and Practices, 10(4), 23, -25.

-Grayson, H. Walker Teaching Resource Center. (2003). Designing Tests. The University of Tennessee at Chattanooga. February.at: http://searchsoftwarequality.techtarget.com/definition quality assurance

-Lam T.C.M. (1995). Fairness in Performance assessments. College Park, MD: ERIC Clearinghouse on Assessment and Evaluation. (ERIC Document Reproduction Service no. ED 391982).

- Philosophe: A thoughtful approach to stuff. http://philosophe.com/testing/

"Rubrics - Definition, Examples". Retrieved 2013-02-

03. https://en.wikipedia.org/wiki/Rubric_(academic)
-League of Arab States; General Secretariat of the Department of Education and Scientific Research, and the United Nations Children's Fund, UNICEF - (2009). Guiding framework for Arab teacher performance standards. Cairo.

-Darwaza, AfnanNazeer. (2000): Theory in teaching and its practical translation. Amman, Jordan - Sunrise House. - Al-Saadawi, Abdullah and Al-Shamrani, Saleh (2016) Education based on standards. Kingdom of Saudi Arabia, Riyadh - Arab Bureau of Education for the Gulf States.

-Shehata, Hassan and Najjar, Zainab, Ammar, and Hamed. (2008). Dictionary of educational and psychological terms, Cairo, the Egyptian Lebanese House.

Al-Sharman, Atef (2019), Education Design for Digital Content, Amman - Dar Al-Masirah.

- Michael, Emtanius (2016). Fundamentals of Measurement and Evaluation in Education and Psychology, Jordan, Amman - Dar Al-Hurricane.

- Al-Mallah, Tamer (2012). E-bags via the web, http://kenanaonline.com/users/tamer2011com/posts/576409

-Abdallah, Safaa Hassan Eissa (2003): The Effectiveness of Portfolio on Developing the Reading and Writing Skills of EFL Students at the Secondary Stage. A Nonpublished Dissertation Submitted for the Ph.D. Ain Shams University.

- Burke, Kay (1999): Authentic Learning. Sky light Training and Publishing Inc. 